International Journal of Instruction e-ISSN: 1308-1470 • www.e-iji.net
April 2019 • Vol.12, No.2

p-ISSN: 1694-609X

pp. 559-572

Received: 04/10/2018

Revision: 09/02/2019

Accepted: 18/02/2019

OnlineFirst:17/03/2019

\title{
Analysis of Discourse Markers in Essays Writing in ESL Classroom
}

\section{Asmaa Al-khazraji}

The British University in Dubai, Dubai, asmaa.alkhazraji@gmail.com

|

Discourse markers improve the quality of writing and increase the comprehension of text. This paper attempts to throw more light in measuring the students' knowledge about Discourse Markers. This paper aims to exponentiate the Discourse Markers in ESL students' essay writing. The Qualitative data was collected from intermediate students of grade 9 from a school in Dubai. Six of their essays were chosen randomly and only nine extracts were analyzed. These extracts focus on how students use Discourse markers with cohesion and coherence. The findings were categorized into three parts: Misused Discourse Markers', Overused Discourse Markers', and Advanced used Discourse Markers'. Based on the results, opportunities for further studies were underlined and recommendations were proposed.

Keywords: discourse markers, coherence, cohesion, student, writing, ESL Classroom

\section{INTRODUCTION}

"Reading maketh a full man; Writing maketh a complete man".

Francis Bacon (in Anderson, 1948)

Writing skill plays a prominent representation of a professional demeanour in Education. Many researchers have insisted on Writing as a formal means of communication (Fraser, 1999; Kamali \& Noori, 2015; Rahimi, 2011; Sun, 2013). Sanford (2012) emphasizes on the importance of developing writing competency. The primary objective in Education is to enhance the writing skills of the students, so that it can be used in different social situations to exemplify complicated intellectual activity. Along the same line, Chow (2007) interprets that writing as a fundamental instrument which aids learners to understand the concepts and ideas better. However, Siniajeva (2005, in Yunus \& Haris, 2014) points out that writing includes rare or unusual situation, since it is deduced from the written work.

Discourse Markers are a linguistic strategy which enables learners to accomplish effective writing. In Academic writing, the efficient utilization of Discourse Markers is an essential element and the shortage of it is seen as a novice error among the second language writers. Eventually, Discourse Markers contribute as building blocks which 
facilitate the textual flow for the reader. In addition, Discourse Markers create discourse coherent discourse which is considered as the essence and substance in Academic writing (Karaata et al., 2012). This is confirmed by researchers such as Martinez (2004) who points that Discourse Markers are a group of signals that add Coherence and Cohesion to the discourse. Thus, Zhao (2013) finds that Discourse Markers do not only provide an unobstructed communication, but also provide coherence to the discourse.

According to Kamali and Noori (2015), Discourse Markers focus on cohesion in the writing operation. The many problems faced by ESL students in the case of coherence in writing can also be rectified. They also indicate that in English classes, students are more interested on a word and sentence level, instead of the textual coherence; though the latter is essential in writing of an essay.

In fact, the significant of Discourse Markers does not only rely on semantic or syntactic features of the structural part, but they also rely on the pragmatic features of the message building, that cause using communicative context (Kamali \& Noori, 2015).

The main purpose of this research is to discover how Discourse Markers are used in students' writing essay in ESL classroom. In particular, this study is conducted to answer the following questions:

Q1: How Discourse Markers are applied in the written essays?

Q2: What is the optimal use of Discourse Markers in the students' written essays?

\section{LITERATURE REVIEW}

\section{Discourse Markers}

According to Tannen et al. (2015) Discourse Markers can be defined as a group of linguistic elements which function in Social, Expressive, Textual and Cognitive Domains. They are phrases and word that relate one section of a discourse to another. They are techniques that reflect Selection of Management, Organization, and Monitoring used by the writer or the speaker (Carter \& McCarthy, 2006). Fraser (1998) describes Discourse Markers as "a growth market in linguistics" (p. 54). By this, he emphasizes that these markers focus on study a multifariousness of languages. In the same light, Fraser (1988) elucidates that "lexical expressions which are syntactically independent of the basic sentence structure and have a general core meaning which signals the relationship of the current utterance to the prior utterance" (p. 29).

Discourse markers have a prepense impingement on writing. They supply unity to the text; it links the ideas to the write-up. Schiffrin (1987) asserts that Knowledge of Discourse Markers can be used to enhance writing skill. To shed more light on this area, Ali et al. (2012) suggest that Discourse Markers aid learners to develop their writing ability by linking the sentences and paragraphs efficiently. They present the semantic and the logical connections between the first learning and the second one. They also simplify interpretation of readers, effectively of all homilies. In the same context, Swan (2005) states that Discourse Markers empower writers to create more understandable context to readers and restrain their explanation of text through utilizing Discourse 
Markers efficaciously. Therefore, knowing how to practically adopt Discourse Markers, can adversely affect the general quality of discourse generated by ESL learners.

Rahimi (2011) refers that Discourse Markers are an important element of communicative competence which aids students to produce meaningful and fluent sentences in ESL. In the same line, Al-Kohlani (2010) accentuates that Discourse Markers play as a tool in the acquisition of communication in the text. On the other hand, some researchers such as Jucker and Ziv (1998) point out that the Discourse Markers not only fall short in the content of semantic, but also in phonological and syntactic characteristics. Further, Schiffrin (1987) describes markers as having fuzzy meaning.

Conferring to the Rhetorical Structure Theory (RST), Taboada and Mann (2006) confirm that Markers focus on linking text and its paragraph, in the organization of the textual meaning. They also indicate that this theory reinforces coherence through proposing a hierarchical, connects textual organization, the role of every text, the relationship between the parts and its essay. Indeed, Sanford (2012) portrays that Discourse Markers provide the generic components, inculcates the sentences' meaning and expressions of the communicative proficiency as well as realistic message capability. Besides, it plays an indispensable stint in encouraging both writer and reader to comprehend better and help in textual comprehension (Eslami \& Eslami, 2007). Further, Dergisi' (2010) aligns with this notion that a worthy writing does not depend only on grammar, but also on cohesion and coherence. In addition, he recounts the importance of taking these Markers into consideration rather than ignoring them, especially in teaching of English writing.

\section{Discourse Markers Function}

Many researchers indicate that the function of Discourse Markers is to lead a crucial role in Academic writing. Fraser (1999), one of the main theoreticians in this field, suggests that Discourse Markers are mainly taken from grammar: Prepositional Phrases, Adverbs, and Conjunctions. The Fraser's taxonomy divides Discourse markers into three central subclasses which are; First, Contrastive Markers that interprets a clear explanation of the following sentence differences from the preceding one. Second, Discourse Markers are Elaborative Markers that show a quasi-parallel connection between the sentences. The final Discourse Markers are Inferential Markers that pinpoint that the second sentence arguments and consummates from the first one. However, he distinguishes supplementary Discourse Markers' subclasses that identify the second sentence to give a reason for the content obtainable in the preceding one such as because, since, after all, and for that/this reason. He also focuses in his clauses, which is related to the Markers. In this characteristic, Hellermann and Vergun (2007) state that the main function of Discourse Markers is to create a link between grammatical units and the topics in discourse.

Nattinger and Decarrico (1992) point that Discourse Markers' functions do not only refer to the connection between a part of discourse and another, but also, they configure subordinate and coordinate patterns by aligning the dissemination at different standards. 
The function of these Markers increases the capacity to utilize the language in a flexible way and facilitate with the ongoing text (Tannen et al., 2015). Further, Fraser (1998, 1999) shows that it controls the textual interpretation conveyed in one section in relation to another section, by imposing a connection between them. However, Watts (1988) reiterates on the preponderance of understanding Discourse Markers as a category of functional-pragmatic, but not as an official or Morph-Syntactic category, which involves items of linguistic that "mark off one segment of the overall discourse with reference to some other segments" (p. 242).

\section{Coherence and Cohesion in Markers}

Coherence provides flow of ideas in a text that enables the reader to comprehend the text easily and without interruption. Consequently, this increases the quality of writing (Halliday \& Hasan, 1977). Karaata et al. (2012) assert that any problem in Academic writing is related to inappropriate or inadequate exertion of Discourse Markers, which are the dominant cohesion components.

In addition, when Discourse Markers are used minimally, it alters the coherence in writing, particularly at the advanced level (Al-Kohlani, 2010). In contrast, Yunus and Haris (2014) illustrate that the Markers in a text imply both on the micro and macro coherence. In the view of Coherence, it links the semantic connections that include a reliable relationship between the items adjoining the meaning. Yunus and Haris view that coherence abets to combining into paragraphs, and then into parts or sections that shapes a hierarchical form to a text. In other words, it groups various units and parts of a text and improves the structure of it.

Cohesion is considered to be a language surface building that is displayed through both vocabulary and grammar (Baldwin, 2014). In fact, it has always been a central element in Academic writing. It is due to its role to connect the components of the articulation and make one sentence interpretation relies with another (Halliday \& Hasan, 1977). However, Halliday and Hasan classify Cohesion into two categories: Syntactic Cohesive Relationship and Lexical Cohesive Relationship. Syntactic Cohesive Relationship includes References (e.g., Demonstratives, Comparisons, and Personal Pronouns), Conjunction, Substitution, and Ellipsis. Lexical Cohesive Relationships involve Collocation and Reiteration. This classification remains a central instrument for written text analysis studies (Baldwin, 2014).

Tannen et al. (2015) points out that Cohesion analysis, with accordance to Halliday and Hasan on a written text, involves words (because, but to sum up, and, by the way... so on) that is named as Markers and those words function partly similar to those Markers. The researchers also indicate that the distinction in meaning ensue from "the semantic of a word itself or from the propositions in the text" (p. 56). For example, 'and' works as an additive meaning; also, its sense shows text semantic contents. Therefore, whether 'and' provides an opposite meaning than the prior one, it would convey meaning similar to 'on the other hand', and 'but'. The next section presents research method. 


\section{METHOD}

\section{Participants}

The samples for this study were intermediate students of grade nine studying in a private school at the Emirates of Dubai. The age of the participants ranged between 14-15 years from both genders. They belonged to different nationalities; most of them were from the United Arab Emirates, while the others were from the Middle East and other regions. Arabic was their first language and English language was taught as the second language. They had different levels of language proficiency.

\section{Model of Analysis and Research Design}

The analysis of these essays is based on Taboada and Mann's (2006) model which is selected because Cohesion and Coherence are reinforced in the written texts. Through Coherence relations, sentences and clauses are joined for rhetorical purposes such as elaboration, condition, cause, or justification.

Regarding to the study design, the samples of essays were analyzed by the researcher qualitatively. Qualitative analysis is a method of "coding, categorizing, and interpreting data to provide explanation of a single phenomenon of interest" (McMillan \& Schumacher, 2010, p. 367). Cohen et al. (2011) indicate that this method is "distinguished by its merging of analysis and interpretation and often by the merging of data collection with data analysis" (p. 537). It is done in this study to look at the usage and identification of Discourse Markers in accordance to the taxonomy of Halliday and Hassan of Cohesion.

\section{Procedure}

Pupils were taught about Discourse Markers and the way to apply these markers in their writing. Coherence and Cohesion were introduced to ensure effective essays. Students were asked to write a 100-word essay or one page on the given topic. The essay, titled Advantages and Disadvantages of Using the Internet, was given by the teacher as a classroom assignment. These essays were written by hand with a time limit and brainstormed ideas in the classroom environment. Twenty-two essays were collected but only 6 essays were randomly chosen for analysis.

\section{Data Collection Tool and Data Analysis}

Document analysis was used as a tool in this paper. It is an essential style of data collection in the research study because it tends to reality more than the others (Johnson \& Christensen, 2014). This document includes students' written work (essays) in the classroom. It is done in order to reflect the students' understanding and usage of the Discourse Markers.

After the data was collected, it was prepared for analysis. The researcher read the data many times before the hand-coding analysis. The analysis was based on how the students use Discourse Markers in an appropriate manner. It was checked for the arranging of the information and notion in an ornate style. Further, Discourse Markers 
provide Writing logical sequences or arrangements, particularly with Coherence and Cohesion. The data was analyzed and categorized according to the level of using Discourse Markers. These levels are: Discourse Markers' Misused, Discourse Markers' overused, and Discourse Markers' advance used.

\section{Trustworthiness of the Study}

Trustworthiness of the current study starts from selecting the data method to answering the questions. In other words, it elucidates every part of the analysis procedure starting from the research design concept in relation to the research model to collecting and analyzing data. Because the researcher role is self-reflective, this interpretative study meets the main factors of trustworthiness which are: Credibility, dependability, and confirmability. Therefore, the quality of the results is considered high. Transferability factor, however, cannot be generalized or applied to another setting, because what occurred in this study may not happen in other classes. Thus, this type of trustworthiness is low, as qualitative research is context-bound.

\section{FINDINGS}

The central aim of this study was to analyze how Discourse Markers are used in students' essay writing under Taboada and Mann's (2006) theory. It links the parts of a text by using Discourse Markers with Cohesion and Coherence. Besides, students in their writing made several errors that will also be clarified in this section. This section is classified into Discourse Markers' misused, Discourse Markers' overused, and Discourse Markers' advance used.

\section{Discourse Markers' Misused}

Based on the excerpts from the respondents, it was found that some of the students misused Discourse Markers' in their sentences. The frequent misuse led to wrong comprehension between classes and sentences.

\section{Excerpt 1:}

But, sitting and not doing anything for a long period of time while using the internet is a bad idea when it could lead to medical problems. Because of the long usage of the Internet, there were some individuals which showed symptoms of eye fatigue, back pain, and obesity.

In Excerpt I, it is not appropriate to use 'But' as a discourse marker in the beginning of the sentence. The function of the Discourse Marker 'but' (coordinating conjunction) is to link the two clauses. The second clause elaborates the meaning of the first sentence. This means that there is no contrast between the two clauses for the student to use this marker. Secondly, it is not appropriate to use the marker 'When' in the sentence. In fact, this marker does not show condition or time in that sentence. The student wants to define the 'bad idea' with wrong marker because 'when' is used to give reason for previous utterance. The discourse markers in this Excerpt are not utilized appropriately semantically or syntactically. Therefore, this misused discourse maker could mislead the reader in relating the two segments. 


\section{Excerpt 2:}

People could be informed of the many knowledge and information the Internet contains, they could also find new ideas and thoughts in it. And it could help them in the future. Students and teens especially are considered the majority in using the Internet....Teens mostly use the Internet for entertainment purposes and social media but using it for studying. The Internet inspires them by many blogs and websites that contribute in expanding their knowledge in their many different interests and hobbies. And it offers postgraduate students job opportunities easily.

In Excerpt 2, the student utilizes the Discourse Markers in the inappropriate position. For example, since 'and' acts as a coordinating conjunction that links the two different clauses. It is not appropriate to begin a sentence with it. The student tries to connect the two sentences or provides another relevant idea with this marker. The discourse marker 'but' is misused, it does not refer to any contrasting idea in the sentence. On the contrary, the student adds more information related to the previous sentence. Thus, the marker is irrelevant to the sentence, because it does not support the previous statement. This weakens the coherence and cohesion of the sentences.

\section{Excerpt 3:}

Finally, there are other disadvantages such as spamming, leakage of private information while shopping online, kids exposed to adult-only content, fraud, and neither. Users need to avoid such happenings by protecting their devices as much as they can. In the other way, it could lead them to scamming and swindling.

In Excerpt 3, the student uses a bizarre combination of the discourse 'and neither'. Although the marker 'neither' indicates negative meaning, it does not disprove the first statement. The discourse marker 'and' is used for more elaboration, it is inappropriate to use at the end of the sentence without adding any information after it. Particularly, the student continues to enumerate examples of the disadvantages in using the internet. This casual usage of the discourse marker impacts negatively on the context and the grammatical unit in the sentences. In addition, 'in the other way' is used incoherently because it does not connect the first statement with the second one. This means that this connector is used to contrast the previous statement. Since, the second statement is a causative of the previous one, choosing 'in the other way' connector breaks the flow of the idea. It seems that the student misunderstood the logical use of these markers.

\section{Discourse Markers' Overused}

There are several learners who apply discourse markers extensively in their essay writing such as in

\section{Excerpt 4:}

There are lots of risks concerning the usage of the Internet, such as physical issues. This issue could lead to eye fatigue and influence eye sight in children and adults. It could also lead to obesity from sitting down for a long period of time. Obesity in people 
is a dangerous issue and should be focused on and people need to be taught the healthy lifestyle of living in the future.

In Excerpt 4, the student does not use a variety of Discourse Markers. The word 'and' is unnecessarily and excessively manipulated. It is exploited more than once in order to extend and elongate the sentence. It is used twice in a sentence and does not give complete meaning. Here, the student does not apply the function of the marker 'and' to link between the topic and the grammatical unit through this overuse. This leads to a steep dip in the decrease in the coherence of the sentences and loses the continuity in the ideas.

\section{Excerpt 5:}

There are many occurrences of fraud from the Internet. Such as that theft incidents occurred because of cyber criminals, by using illegal techniques and activities. Users try to avoid such cases by downloading or purchasing applications and programs that hackers or cyber criminals cannot approach their data or personal information that there are also common cases of mail spamming that are really disturbing because they could get mixed with other important emails and they are also illegal. After that, people can advertise their products to random individuals.

In this Excerpt, the student also does not have any variety in the usage of Discourse Markers. There is an imperceptible usage in the way of using Discourse marker. The main function of 'that' is to refer to the previous noun. In this case, its function is not applied accurately in linking the two clauses or referring to the previous noun. In addition, it is used thrice in a single sentence. It is used needlessly in the first sentence and it creates disorder in the textual meaning. It is applied at the wrong position in the sentence and there is no clause before it. The stereotyped exertion of 'that' is to draw the reader's attention away from the content. The reason behind this is that the reader loses the main idea of the paragraph when reading a long sentence 'Users try to avoid.... random individuals' connected by the descriptive marker 'that'. The student does not break the sentence into smaller sentences and not use different Discourse Markers.

\section{Excerpt 6:}

Also, there are viruses and malicious programs that come from the Internet that could severely damage a device's software and causes it to malfunction and so as losing important data. Through shopping online, people tend to send their credit card details when as they purchase products, which is a very vulnerable process that could lead to leakage of private information if not dealt with caution..... Later that, it could affect a person's social skills greatly by spending lots of time using the Internet.

In Excerpt 6, there are different kinds of overused Discourse Markers. The student frequently uses variety in the Discourse Markers, but they are subjugated to one time in each sentence. For example, the markers 'so as' creates incongruous sentences, because the marker 'so' refers to the consequence or result, while 'as' refers to the cause or reason. It is improper to use both of them at one time, since each one has its own function which is entirely different from the other. Therefore, 'so as' is used 
wrongly to prompt the reason. The same thing occurs with 'later that' and 'when as' is used mistakenly; because 'later' and 'when' refer to the time, while 'that' shows the identification or description and 'as' refers to the cause. These markers imply that the markers' function as a tool of facilitating comprehensible input is distorted. This means that this practice has a negative impact in building a correlation with reader and the text. Consequently, it interrupts the comprehension and the writer's semantics.

\section{Discourse Markers' Advance Used}

Some students use advanced Discourse Markers in their essays. Such as in

\section{Excerpt 7:}

Some of its benefits are providing quick communication. Indeed, it has provided a podium for many to express their opinions and explore different cultures and societies through many applications that offer these services..... It also has given many job opportunities to the public, made research easier for students and researchers, and granted people with unique tastes the chances to further explore their interests.

In Excerpt 7, the student successfully accounts the Discourse Marker 'Indeed' in a reasonable way. It is used to affirm the first statement and to extend the discussion in the second statement. This Marker enables the student to show his/her attitude about using the internet for communication purposes. So, the student chooses and utilizes this marker correctly to express his/her idea. The Markers 'also' and 'and' have the same function. They are used to add or sequence other benefits of the internet. The student succeeds in using the marker 'also' at the beginning of the sentence to connect the second sentence with the previous one and uses the marker 'and' in the middle of the sentence to connect the sentences in a series. These elaborative markers 'and' and 'also' link the text's segments, maintain textual cohesion, and add meaning to the text. In fact, it seems that the student knows the function of these markers and exploits them in an adept manner. This enables the reader to read the text fluently and naturally.

\section{Excerpt 8:}

Many different subjects from the different parts of Earth were available to all users and that consequently leads under-aged children getting exposed to age-inappropriate content. However, their safety can be protected through monitoring the sites they use and blocking any harmful ones, and while that may not be effective for some, it will suffice for most. Discussing such a controversial topic among parents will be effective in suggesting more solutions. Moreover, educating children on the correct usage of the internet and which age-appropriate content to browse will be helpful.

In Excerpt 8, the Discourse Markers are well-distributed and handled correctly. 'Consequently' for instance, means 'as a result' is customized to portray the cause and effect. It connects the two clauses and marks the second clause to be an explanation to the first conclusion. This inferential marker is used effectively to provide reasoning. The marker 'However' is also embedded appropriately to display the contrast with the preceding statement. This connective is used to link the two different ideas in one 
paragraph. In terms of linguistic semantics, its position is also suited to the flow of the topic. Additionally, 'Moreover' adds more information and supports the previous sentences in the same paragraph. This elaborative marker is formulated successfully in developing and extending the idea about how children can use internet with safety. Thus, this exceptional use of these markers provides a good cohesion and minimizes disruption. It enhances the readers to comprehend the intended content. They enable the student to relate the grammatical components with the topic. The student was felicitous in his/her choice of these markers. Accordingly, the quality of writing is developed effectively.

\section{Excerpt 9:}

The Internet has been a huge helping hand for many individuals all over the world, and still is demanded presently. It has such admirable characteristics that make students began using it. Besides, it is a huge benefit for many office workers, doctors, engineers, writers, artists, and many other occupations that require the Internet's services. Although the Internet's usage should cause no harm, it started causing a lot of issues regarding health because of the misuse of students especially, and people generally, within the web.

In Excerpt 9, the student exemplifies in the usage of Discourse Markers in an appropriate and effective style. For example, the marker 'beside' is used to add emphasis to the meaning and structure of the sentence. He/she supports the previous idea by adding another point slightly different but focuses on the same topic. In other words, the student with this marker still focuses on the benefits of internet usage by adding another advantage (i.e. using it in the working places). However, the Marker 'although' is mobilized to show contradiction in the following sentence. This marker is managed effectively not only to emphasize the contrast between the two clauses, but also to represent the connectivity between the two ideas. The markers 'beside' and 'although' are used in a professional and an adept style. The student was right to choose markers apt to the context. These markers increase the cohesion and coherence of the text. Then, the idea becomes undeterred and readers understand it with clarity.

This section analyzed the essays of students according to their usage of the discourse markers under the categories misused, overused, and advanced used discourse markers. The next section will discuss the findings of this study.

\section{DISCUSSION}

This study aims to analyze the manner of the application of Discourse Markers ESL intermediate students in their own essay writing. The interpretations of Discourse Markers are explored with essential findings, that link to the literature review.

Drawing from the analysis, it is inferred that Discourse Markers are not only required for linking paragraphs or sentences (Ali et al., 2012; Al-Kohlani, 2010; Carter \& McCarthy, 2006; Fraser, 1998, 1999; Tannen et al., 2015; Watts, 1988; Yunus \& Haris, 2014), but also for constructing Knowledge from the Known to the Unknown (Dergisi, 2010; Yunus \& Haris, 2014). Thus, it is found without cohesion and coherence, the 
reader faces difficulties to comprehend the idea that the writer attempts to bring about in his essay (Halliday \& Hasan, 1977; Karaata et al., 2012).

Subsequently, it is noticed that the grammatical function of Discourse Markers is quite important and inevitable to convey the content efficaciously. In other words, grammar structures essay writing and the misuse of it revamps the quality of writing (Fraser 1998, 1999; Hellermann \&Vergun, 2007). A Marker functions as an assortment, as it programmed to be multi-faceted and summates importance to the text (Nattinger \& Decarrico, 1992). Another important aspect is observed in those advanced uses of the students. These Markers not only focus on grammatical component, but also concentrate on the objective and the content of their writing (Fraser, 1999; Hellermann \& Vergun, 2007). This means that through Discourse Markers, the students are able to connect the topic with the grammatical components (Hellermann \& Vergun, 2007).

Regarding, the misuse and overuse of the Discourse Markers, there are instances, where such situation affects negatively the message transmission in text, overriding the basic role of Discourse Markers (Al-Kohlani, 2010; Rahimi, 2011; Sanford, 2012; Swan, 2005). It is found that the mistake in the use of Discourse Markers disturbs directly on the style of the pupils' writing (Karaata et al., 2012; Tannen et al., 2015). Therefore, these markers facilitate in understanding of the written text (Eslami \& Eslami, 2007; Swan, 2005). The following section introduces the conclusion and some recommendations.

\section{CONCLUSION AND RECOMMENDATIONS}

Discourse Markers are a significant aspect in academic writing. Markers build cohesion and coherence in writing and convey ideas meaningfully to the readers. The text would be constructed illogically and there would be no continuation in the sentences and paragraphs. There are various types of Discourse Markers and each one expresses a different meaning. This study sheds more light on the effects of Discourse markers in writing. There are many studies that focus on particular types of Discourse Markers. This study aims to evaluate the quality use of Discourse Markers in writing. In particular, it focuses on the essays of the second language learners.

This study insists on Discourse Markers as indispensable components of quality writing. This importance lies in facilitating comprehension ideas in the text. These markers add meaning to the sentences and paragraphs. Discourse Markers enable the flow of communication to flow without any disruption. The readers are provided inputs on the organization of the text. They assist readers to enunciate the introduction and conclusion with the assistance of discourse markers. Markers are important in academic writing and they should be utilized only when necessary. The method used for the present study is a qualitative approach. Several essays were collected, from a school in Dubai, and analyzed by the researcher. This study follows Taboada and Mann (2006) theory in analyzing the essays. The analysis focused on evaluating the use of Discourse Markers in their essay writing. In particular, it highlights the usage of Discourse markers with coherence and cohesion.

The findings of this paper are constituted into three sections; misused, overused and 
advance used discourse markers. Many types of discourse markers are used in the students' essays such as inferential, elaborative, causative, and contrastive markers. Some of them are used appropriately, while others are not. It is also found that there is a strong relationship between the discourse markers and the quality of writing. They impact on the easy understanding of the topic and the flow of ideas in a flexible manner. Jalilifar (2008) points out that "DMs, besides other textual characteristics, help identify good and poor writings, and more importantly, the quality is tapped by the use of wellfunctioned DMs". In addition, these markers are the keys of enhancing cohesion and coherence in writing. When these makers are misused or overused, they can impact negatively on the communication of ideas and on the quality of writing. This is confirmed by Aidinlou and Shahrokhi mehr (2012), who say that "comprehension of DMs and cohesive relations, on one hand, and overall creation of a text, are highly interrelated".

To sum up, this paper provides a valuable contribution to second language learning. It focuses on the role of discourse markers in improving the quality of writing. There are also some recommendations drawn from this study. It was suggested for the pupils to be taught how to apply Discourse Markers specifically in their writing. Students should be made aware about the function of these markers. They should have a clear knowledge of the Discourse Markers and should be able to use it in the given context. Finally, Cohesion and Coherence are things that should be taken into consideration while applying the markers effectively. These recommendations hoped to improve the crucial area of language studies. It is also hoped that this study can aid and provide other researchers some valuable vision within Discourse Markers. Proceeding from these results, further studies and researches can be conducted are needed in the same field to recuperate students' writing.

\section{REFERENCES}

Aidinlou, N., \& Shahrokhi mehr, H. (2012). The effect of discourse markers instruction on EFL learners' writing. World Journal of Education, 2(2), 10-16. https://doi:10.5430/wje.v2n2p10.

Ali, S., Kalajahi, R., \& Abdullah, N. (2012). Discourse connectors: An overview of the history, definition and classification of the term. World Applied Sciences Journal, 19(11), 1659-1673.

Al-Kohlani, F. (2010). The function of discourse markers in Arabic newspaper opinion articles (Doctoral dissertation). Georgetown University.

Anderson, F. (1948). The Philosophy of Francis Bacon. Chicago: University of Chicago Press.

Baldwin, E. (2014). Beyond contrastive rhetoric: Helping international lawyers use cohesive devices in U.S. legal writing. Florida Journal of International Law, 26(3), 399-446. doi: https://ssrn.com/abstract=2628445.

Carter, R., \& McCarthy, M. (2006). Cambridge grammar of English. Cambridge, UK: Cambridge University Press. 
Chow, T. (2007). The effects of the process-genre approach to writing instruction on the expository essays of ESL students in a Malaysian secondary school (Doctoral dissertation). University Sains Malaysia.

Cohen, L., Manion, L., \& Morrison, K. (2011). Research methods in education (7th ed.). London: Routledge.

Dergisi, U. (2010), Discourse markers in English writing. The Journal of International Social Research, 3(11), 299-305. doi: http://www.sosyalarastirmalar.com/cilt3/sayi11pdf/feng_li.pdf.

Eslami, Z., \& Eslami-Rasekh, A. (2007), Discourse markers in academic lectures. Asian EFL Journal, 9(1), 22-38. doi: http://www.asian-efl-journal.com.

Fraser, B. (1988), Types of English discourse markers. Acta Linguistica Hungarica, 38(1-4), 19-33.

Fraser, B. (1998), Contrastive discourse markers in English. In A. Jucker \& Y. Ziv, Discourse markers: Description and theory (pp. 301-326). Philadelphia: John Benjamins Publishing Company.

Fraser, B. (1999), What are discourse markers? Journal of Pragmatics, 31(7), 931-952. doi: http://10.1016/s0378-2166(98)00101-5.

Halliday, M., \& Hasan, R. (1977). Cohesion in English. London: Longman.

Jalilifar, A. (2008). Discourse Markers in Composition Writings: The Case of Iranian Learners of English as a Foreign Language. English Language Teaching, 1(2), 114-122. http://doi:10.5539/elt.v1n2p114.

Johnson, B., \& Christensen, L. (2014). Educational research; Quantitative, qualitative, and mixed approaches (7th ed.). California: SEGE publications.

Jucker, A., \& Ziv, Y. (1998). Discourse markers (pp. 301-326). Philadelphia: John Benjamins Publishing Company.

Kamali, F., \& Noori, H. (2015). The impact of discourse markers instruction on improving writing of intermediate EFL learners. Science Journal, 36(3), 944-949. doi: http://dergi.cumhuriyet.edu.tr/cumuscij.

Karaata, C., Cepik, C., \& Cetin, Y. (2012). Enhancing the use of discourse markers in academic writing: The combination of incidental al acquisition and explicit instruction. Electronic Journal of Social Sciences, 11(40), 11-29. doi: www.esosder.org

Martinez, A. C. L. (2004). Discourse markers in the expository writing of Spanish university students. IBÉRICA, 8, 63-80.

McMillan, J., \& Schumacher, S. (2010). Research in education; Evidance- based inquiry (7th ed.). Boston: Person.

Nattinger, J., \& DeCarrico, J. (1992). Lexical phrases and language teaching. Oxford [England]: Oxford University Press. 
Rahimi, M. (2011). Discourse markers in argumentative and expository writing of Iranian EFL learners. World Journal of English Language, 1(2). doi: http://10.5430/wjel.v1n2p68.

Sanford, S. (2012). A comparison of metadiscourse markers and writing quality in adolescent written narratives (Doctoral Dissertation). The University of Montana.

Schiffrin, D. (1987). Discourse markers. Cambridge [u.a.]: Cambridge Univ. Press.

Sun, W. (2013). The importance of discourse markers in English learning and teaching. Theory and Practice in Language Studies, 3(11). doi: http://10.4304/tpls.3.11.21362140 .

Tannen, D., Hamilton, H., \& Schiffrin, D. (2015). The handbook of discourse analysis (2nd ed.). Oxford: Wiley-Blackwell Publishing.

Swan, M. (2005). Practical English usage. Oxford: Oxford University Press.

Taboada, M., \& Mann, W. (2006). Rhetorical structure theory: looking back and moving ahead. Discourse Studies, 8(3), 423-459. doi: http://10.1177/1461445606061881.

Watts, R. J. (1988). A relevance-theoretic approach to commentary pragmatic markers: The case of "actually", 'really" and "basically". Acta Linguistica Hungarica, 38, 235260.

Yunus, M., \& Haris, S. (2014). The use of discourse markers among form four SLL students in essay writing. International Education Studies, 7(2). doi: http://10.5539/ies.v7n2p54.

Zhao, H. (2013). A study on the pragmatic fossilization of discourse markers among Chinese English learners. Journal of Language Teaching and Research, 4(4), 707-714. doi: http://10.4304/jltr.4.4.707-714.

Siniajeva, I. (2005). Discourse markers: Their functions and distribution across registers. In Yunus, M., \& Haris, S. (2014). The use of discourse markers among form four SLL students in essay writing. International Education Studies, 7(2). doi: http://10.5539/ies.v7n2p54 